\title{
Phenylketonuria Pathophysiology: on the Role of Metabolic Alterations
}

\author{
Patrícia Fernanda Schuck ${ }^{*}$, Fernanda Malgarin1, José Henrique Cararo ${ }^{1}$, \\ Fabiola Cardoso ${ }^{2}$, Emilio Luiz Streck ${ }^{3}$, Gustavo Costa Ferreira ${ }^{2}$
}

\begin{abstract}
${ }^{1}$ Laboratório de Erros Inatos do Metabolismo, Unidade Acadêmica de Ciências da Saúde, Universidade do Extremo Sul Catarinense, Criciúma, SC, Brazil

${ }^{2}$ Instituto de Bioquímica Médica Leopoldo de Meis, Universidade Federal do Rio de Janeiro, Rio de Janeiro, Brazil ${ }^{3}$ Laboratório de Bioenergética, Unidade Acadêmica de Ciências da Saúde, Universidade do Extremo Sul Catarinense, Criciúma, SC, Brazil.
\end{abstract}

[Received July 16, 2015; Revised August 25, 2015; Accepted August 27, 2015]

\begin{abstract}
Phenylketonuria (PKU) is an inborn error of phenylalanine (Phe) metabolism caused by the deficiency of phenylalanine hydroxylase. This deficiency leads to the accumulation of Phe and its metabolites in tissues and body fluids of PKU patients. The main signs and symptoms are found in the brain but the pathophysiology of this disease is not well understood. In this context, metabolic alterations such as oxidative stress, mitochondrial dysfunction, and impaired protein and neurotransmitters synthesis have been described both in animal models and patients. This review aims to discuss the main metabolic disturbances reported in PKU and relate them with the pathophysiology of this disease. The elucidation of the pathophysiology of brain damage found in PKU patients will help to develop better therapeutic strategies to improve quality of life of patients affected by this condition.
\end{abstract}

Key words: brain; hyperphenylalaninemia; metabolic alterations; phenylalanine; phenylketonuria

First described in 1934 by Abjörn Fölling, phenylketonuria (PKU; OMIM \# 261600) is an autosomal recessive inborn error of L-phenylalanine (Phe) metabolism. Phenylketonuric patients present with high Phe concentrations in their tissues and hyperphenylalaninemia (HPA) due to total or partial deficiency of phenylalanine hydroxylase (PAH; EC \# 1.14.16.1) activity, as well as low tyrosine (Tyr) concentrations [1]. Phe is an essential amino acid obtained exclusively by the diet or by proteolysis. It is crucial for protein synthesis, as well as for the synthesis of Tyr and its derivatives, such as dopamine, norepinephrine, and melanin $[1,2]$. The major metabolic Phe pathway involves its hydroxylation to Tyr by PAH, found mainly in liver, but also in kidney [3,4]. Alternative pathways are less significant and include Phe transamination in its alanine side-chain forming phenylpyruvic acid (PPA), that is catalyzed by the enzyme phenylalanine (histidine) transaminase (EC \# 2.6.1.58), found mainly in liver. Since this reaction is activated by substrate, it becomes more relevant in the events of high Phe blood levels [5]. Phe can also undergo decarboxylation to phenylethylamine, although at low rates, by the action of phenylalanine decarboxylase (EC \# 4.1.1.53) [6] (Figure 1).

There are many mutations in the $P A H$ gene (localized in the chromosome 12q) already described [7-9]. Rigorous Phe-restrict diet is the cornerstone of therapeutic PKU management [10,11]. Improved clinical findings are ascribed to dietary therapy in phenylketonuric patients, particularly decreasing aberrant plasma Phe levels $[12,13]$. Nevertheless, some putative side effects have been associated to this therapy, including zinc, selenium and iron deficiencies [14]. Copper, zinc [15], magnesium [16], and selenium [17] plasma levels in PKU treated children are significantly decreased, as compared to nonPKU children. 


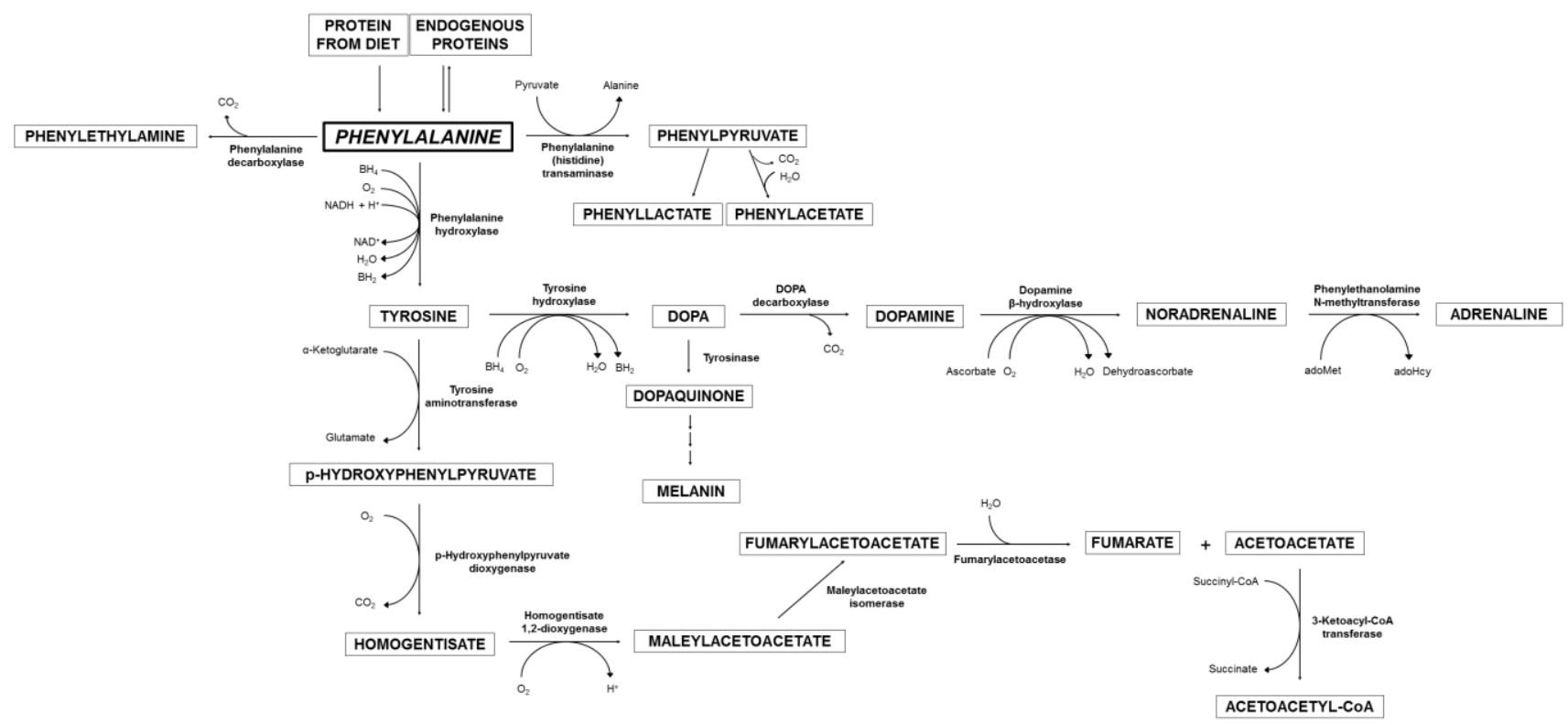

Figure 1. Phenylalanine metabolism. Most of phenylalanine obtained from diet or endogenous proteolysis is hydroxylated producing tyrosine by phenylalanine hydroxylase, which is deficient in PKU. Additional routes include transamination to phenylpyruvate and decarboxylation in order to synthesize phenylethylamine.

The main findings presented by phenylketonuric patients are severe neurological damage, including corpus callosum, striatum, and cortical alterations and hypomyelination, that result in intellectual deficit and neurodegeneration [18-21]. However, the pathophysiology underlying the brain damage is not well understood yet. The main hypothesis is that Phe and its metabolites act as neurotoxins in the brain. Some pathomechanisms involving metabolic alterations are proposed and will be discussed below.

\section{Oxidative stress}

Oxidative stress is defined as the lack of balance between reactive oxygen/nitrogen species production and the antioxidant system [22]. Such imbalance may induce oxidative damage to proteins, lipids, or DNA. In fact, oxidative stress has been associated with the pathophysiology of several neurodegenerative diseases, including Parkinson's and Alzheimer's disease, epilepsy, and demyelination [22-30]. It has been demonstrated that the brain tissue is particularly vulnerable to oxidative stress due to high $\mathrm{O}_{2}$ consumption, high tissue concentrations of iron, low level of antioxidant defenses, the presence of excitatory amino acids and dopamine metabolism, which generate hydrogen peroxide [22].

Over the last years, oxidative damage to macromolecules has been investigated in HPA animal models and biological samples from PKU patients. It was demonstrated that high Phe levels are associated with DNA, protein, and lipid damage, as well with decreased antioxidant defenses in phenylketonuric patients. In this scenario, DNA damage was reported in peripheral blood from PKU patients in vivo and in vitro in a dosedependent manner [31,32]. In addition, protein and lipid oxidative damage, measured by carbonyl formation and sulfhydryl oxidation, and thiobarbituric acid-reactive species (TBA-RS) and malondialdehyde (MDA) content, respectively, were described in plasma and erythrocytes from PKU patients [31,33-36]. Decreased antioxidant defenses, both enzymatic and non-enzymatic, were also found in these subjects. Low levels of plasma total antioxidant status and reactivity, L-carnitine, betacarotene and coenzyme $\mathrm{Q}_{10}$, and altered catalase [CAT], superoxide dismutase [SOD] and glutathione peroxidase [GPx] activities in PKU patients samples indicate an impairment of antioxidant defense that could result in oxidative stress $[31,33,35,36]$. Some of these findings were reversed by L-carnitine and selenium supplementation [37].

HPA animal models also provide relevant evidence for the elucidation of the role of oxidative stress in the pathophysiology of PKU. Several in vivo and in vitro studies show impairment of the antioxidant enzymes CAT, SOD and GPx, as well decreased non-enzymatic antioxidants levels, including alterations in glutathione 
(GSH) metabolism in rat brain tissues. In this scenario, high Phe concentrations also increases sulfhydryl oxidation, TBA-RS and MDA levels, and 2',7'dichlorofluorescein (DCFH) oxidation, indicating protein and lipid oxidative damage and increased production of reactive species of oxygen, respectively [38-43]. Most of these findings were prevented by supplementation with lipoic acid, melatonin, alpha-tocopherol and/or ascorbic acid, which are potent and well-known antioxidants [22]. Furthermore, in vitro and in vivo DNA damage was found both in patients $[32,44]$ and animal models [45] and it was proposed that it is associated with oxidative damage.
In vitro experiments demonstrated that the Phe-derived metabolites PPA, phenyllactic (PLA), and phenylacetic (PAA) acids, which also accumulate in PKU, affect antioxidant enzymes. While PLA and PAA increase SOD activity in rat brain tissue, PPA decreases glucose-6phosphate dehydrogenase (EC \# 1.1.1.49) in the same tissue [43,46], indicating a possible indirect mechanism by which Phe leads to oxidative stress in PKU. The main findings on disruption of redox homeostasis reported in patients and animal models of PKU are summarized in Table 1.

Table 1. Landmark studies showing oxidative stress in phenylketonuria.

\begin{tabular}{|c|c|c|}
\hline Reference & Sample & Findings \\
\hline Schulpis et al., 2005 & PKU Patients Blood & $\begin{array}{ll}\downarrow & \text { TAS } \\
\uparrow & 8-\mathrm{OH}-\mathrm{DG}\end{array}$ \\
\hline Sitta et al., 2009 & $\begin{array}{l}\text { PKU patients leucocytes; normal } \\
\text { Individuals leukocytes }\end{array}$ & $\begin{array}{l}\uparrow \text { DNA damage index in vivo } \\
\uparrow \text { DNA damage index in vitro }\end{array}$ \\
\hline Sirtori et al., 2005 & $\begin{array}{l}\text { PKU patients plasma and } \\
\text { erythrocytes }\end{array}$ & $\begin{array}{ll}\downarrow & \text { TAR, GPx } \\
\uparrow & \text { TBA-RS }\end{array}$ \\
\hline Sitta et al., 2009 & PKU Patients Blood & $\begin{array}{ll}\downarrow & \text { TAR } \\
\uparrow & \text { TBA-RS }\end{array}$ \\
\hline Sitta et al., 2009 & $\begin{array}{l}\text { PKU patients plasma and } \\
\text { erythrocytes }\end{array}$ & $\begin{array}{ll}\downarrow & \text { GSH, GPx, TAR, SH } \\
\uparrow & \text { TBA-RS, protein carbonyl }\end{array}$ \\
\hline Sanayama et al., 2011 & $\begin{array}{l}\text { PKU patients plasma and } \\
\text { erythrocytes }\end{array}$ & $\begin{array}{ll}\downarrow & \text { TAR, GPx, beta-carotene, Q10 } \\
\uparrow & \text { TBA-RS, MDA-modified LDL, CAT, SOD }\end{array}$ \\
\hline Ercal et al., 2002 & Mice brain and red blood cells & $\begin{array}{ll}\uparrow & \text { MDA, G6PD, CAT } \\
\Downarrow & \text { GSH/GSSG, NADPH }\end{array}$ \\
\hline Kienzle Hagen et al., 2002 & Rat brain & $\begin{array}{ll}\uparrow & \text { chemiluminescence } \\
\Downarrow & \text { TRAP, CAT, GPx }\end{array}$ \\
\hline Martinez-Cruz et al., 2002 & Rat brain and cerebellum & $\begin{array}{ll}\uparrow & \text { Ehrlich adducts, MDA, GSSG, HO-1 } \\
\Downarrow & \text { GPx, GR, MAPK 1/2 }\end{array}$ \\
\hline Fernandes et al., 2010 & Rat brain & $\begin{array}{ll}\uparrow & \text { TBA-RS } \\
\Downarrow & \text { SH, GSH }\end{array}$ \\
\hline Moraes et al., 2010 & Rat brain & $\begin{array}{ll}\downarrow & \text { CAT, SOD, GPx, G6PD, GSH, TRAP } \\
\boldsymbol{\uparrow} & \text { TBA-RS, ROS }\end{array}$ \\
\hline Moraes et al., 2013 & Rat brain & $\underset{\text { TBA-RS, protein carbonyl, SOD, ROS }}{\downarrow}$ \\
\hline Deon et al., 2015 & $\begin{array}{l}\text { Normal individuals plasma; PKU } \\
\text { patients plasma and urine }\end{array}$ & $\begin{array}{ll}\uparrow & \text { DNA damage index } \\
\uparrow & 8-\mathrm{OH}-\mathrm{DG}\end{array}$ \\
\hline Simon et al., 2013 & Rat brain and blood & $\begin{array}{l}\uparrow \text { DNA damage index in vivo } \\
\uparrow \text { DNA damage index in vitro }\end{array}$ \\
\hline Rosa et al., 2012 & Rat brain & $\downarrow$ G6PD \\
\hline
\end{tabular}

CAT - catalase; GPx - glutathione peroxidase; G6PD - glucose 6-phosphate dehydrogenase; GSH - reduced glutathione; GSSG - glutathione disulfide; GR - glutathione reductase; HO-1 - hemeoxygenase-1; LDL - low density lipoprotein; MAPK 1/2 - Mitogen-activated protein kinases; MDA - malondialdehyde; NADPH - nicotinamide adenine dinucleotide phosphate; PKU - phenylketonuria; Q10 - coenzyme Q10; ROS - reactive oxygen species; SH - sulfhydryl group; SOD - superoxide dismutase; TAR - total antioxidant reactivity; TAS - total antioxidant status; TBA-RS thiobarbituric acid-reactive species; TRAP - total radical-trapping antioxidant potential 8-OH-DG - 8-hydroxy-2-deoxyguanosine. 


\section{Neurotransmitters metabolism}

Neurochemical and behavioral studies have demonstrated that animals fed with diets rich in Phe present decreased brain serotonin levels and impaired behavior in some problem-solving tasks [47]. Recently, it has also been demonstrated that these patients are more susceptible to neurological symptoms caused by cerebral dopamine deficiency, such as Parkinsonism [2]. Indeed, several studies have shown that high Phe concentrations is associated with decreased serotonin, dopamine, and norepinephrine levels in human and murine PKU [48-52]. The decrease of these neurotransmitters levels could be related to the effect of high Phe concentration on amino acids transport through the blood-brain barrier (BBB) (such as Tyr and tryptophan - Trp) or on enzymes involved in neurotransmitters synthesis [48]. It is important to stress out that large neutral amino acid
(LNNA) transporter has high affinity for Phe, which competes with other amino acids to cross BBB [53], consequently reducing the amount of Trp and Tyr available for neurotransmitter synthesis $[52,54,55]$.

Phe is also a competitive inhibitor of Tyr hydroxylase (EC \# 1.14.16.2) and Trp hydroxylase (EC \# 1.14.16.4), important enzymes for the brain synthesis of the neurotransmitters dopamine and serotonin, respectively [56-60]. Phe metabolites also inhibit 5hydroxytryptophan decarboxylase/dopa decarboxylase (EC \# 4.1.1.28), another enzyme involved in neurotransmitters metabolism [61]. Such effects collaborate to the impairment of catecholamines in the brain found in PKU patients and animal models. Table II summarizes the main findings on the alterations of neurotransmitters metabolism in patients and animal models of PKU.

Table 2. Landmarks studies showing impaired neurotransmitter metabolism in phenylketonuria.

\begin{tabular}{lll}
\hline Reference & Sample & Findings \\
\hline Güttler and Lou, 1986 & PKU patients urine and CSF & $\downarrow$ dopamine, serotonine, HVA, 5-HIAA \\
Yano et al., 2013 & PKU patients urine and serum & $\downarrow$ melatonin, 6-sulfatoxymelatonin, dopamine \\
Pascucci et al., 2002 & Mouse brain & $\downarrow$ serotonin, Trp, 5-HT \\
Landvogt et al., 2007 & PKU patients & $\downarrow$ fluoro-L-dopamine uptake \\
Sawin et al., 2014 & Mouse brain & $\downarrow$ catecholamines, serotonin \\
Harding et al., 2014 & Mouse brain & $\downarrow$ TH \\
Justice and Hsia, 1965 & Mouse brain & $\downarrow$ 5THD \\
\hline $\begin{array}{l}\text { 5-HIAA - 5-hydroxyindoleacetic acid; 5-HT - 5-hydroxytryptophan; 5HTD - 5-hydroxytryptophan; CSF - cerebrospinal fluid; HVA - } \\
\text { homovanillic acid; TH - tyrosine hydroxylase; Trp - triptophan; Tyr - tyrosine }\end{array}$
\end{tabular}

\section{Protein synthesis}

Investigating Phe effect towards rat brain protein synthesis, Agrawal and coworkers [62] identified an inhibition of $\left[{ }^{35} \mathrm{~S}\right]$ methionine incorporation rate into proteins in 8- and 18-day-old rat brain, as well as decreased $\left[{ }^{35} \mathrm{~S}\right]$ methionine and $\left[{ }^{14} \mathrm{C}\right]$ leucine transport into the brain acid-soluble pool in 18-day-old rats. In vitro studies performed in a cell-free system derived from hamster brain suggested that the failure in protein synthesis caused by Phe might to be due to impairment in the process of initiation [63]. Indeed, it was reported a negative correlation between cerebral protein synthesis rate and supra-physiological plasma concentrations of Phe $(200-500 \mu \mathrm{M})$ [64]. In addition, it was documented that increased plasma Phe concentration was inversely related to cerebral protein synthesis rate, possibly via impaired LNAA transport across BBB [65] and decreased Tyr incorporation into protein in central nervous system in PKU patients [66]. Saturation of L-amino acid transporter at BBB by increased plasma Phe seems to be a contributing but not pivotal factor to the decreased protein synthesis observed in genetic PKU murine models [67].

By using positron emission tomography to study brain of PKU patients after an intravenous L-[1-( $\left.\left.{ }^{11}\right) \mathrm{C}\right]-\mathrm{Tyr}$ administration, Hoeksma and colleagues [68] 
demonstrated a significant negative correlation between plasma Phe levels and the cerebral protein synthesis rate. This implies that Phe levels should be lower than 600-800 $\mu \mathrm{mol} / \mathrm{L}$ to prevent the disruption of protein synthesis. Gropper and coworkers [69] showed that the mean plasma immunoglobulin A (IgA) and immunoglobulin G (IgG) concentrations in PKU children were significantly decreased as compared to values from similar aged healthy children, a finding that could be secondary to a poor nutritional status of Phe-restrict diet therapy. Additionally, Imperlini and colleagues [70] compared cerebral protein expression of homozygous PKU mice to that of their heterozygous counterparts by using an electrophoretic technique and identified 21 differentially expressed proteins, four of which were over-expressed (including Glu2/3 and NRI) and 17 under-expressed (e.g. Ckb, Dpysl2, Eno1, Pgam1, Pkm, and Syn2). Due to the significant role of these proteins on brain physiology, the authors concluded that such pattern of expression may be related to the processes underlying PKU brain dysfunction, namely decreased synaptic plasticity, impaired neurotransmission, and impaired brain bioenergetics. Increased levels of Phe and related metabolites were also associated with impaired biosynthesis of antioxidants enzymes in PKU, connecting the impaired protein synthesis induced by Phe to disruption of redox homeostasis [71]. Despite all these findings, it is still to be clarified whether the decreased protein synthesis is due to an intrinsic toxic effect of high Phe levels in tissues or due to a poor nutritional status of PKU patients under rigorous Phe-restrict diet therapy.

\section{Lipid metabolism}

Several studies have shown that lipid metabolism is impaired in PKU, which could collaborate to the hypomyelination found in patients. In this scenario, Nagasaka and colleagues [72] demonstrated that phenylketonuric patients have altered serum lipoprotein levels, including lower levels of total cholesterol, highdensity lipoprotein (HDL), low-density lipoprotein (LDL), and apolipoprotein A-I/A-II and B. These low cholesterol levels may be explained by the impairment of cholesterol synthesis due to down-regulated expression of 3-hydroxy-3-methylglutaryl coenzyme A reductase (HMGR; EC \# 1.1.1.34), the rate controlling enzyme in the cholesterogenesis, as observed in a knock out murine model of PKU [73]. Furthermore, it has been demonstrated that Phe, PPA and PAA inhibit in vitro the activities of mevalonate 5-pyrophosphate decarboxylase (EC \# 4.1.1.33) and HMGR in chicken liver at concentrations similar to those found in PKU patients [74]. Oxysterols and vitamin D levels, both important metabolites from cholesterol, are also found decreased in serum from phenylketonuric adult patients [75].

In addition, it has been shown that docosahexaenoic acid (DHA) (an essential omega-3 long-chain polyunsaturated fatty acid) levels are lower in plasma phospholipids [76] and in blood samples from phenylketonuric patients [59], and such deficit could collaborate to the neural damage found in this disease [77]. Moreover, PKU patients presented lower concentrations of eicosapentaenoic acid, DHA, and arachidonic acid (AA), as compared with healthy controls [78]. In this context, it has been suggested that Phe and its metabolites affect long-chain polyunsaturated fatty acids biosynthesis by inhibiting a deoxygenize reaction, impairing DHA and AA synthesis [79].

\section{Bioenergetics}

Brain energy metabolism alterations play an important role in the pathophysiology of many inborn errors of metabolism [80-83]. In this context, energy metabolism impairment was reported in HPA animal models and patients. Significant decrease of succinate dehydrogenase (EC \# 1.3.5.1) and mitochondrial respiratory chain complexes I-III activities were detected in cerebral cortex of rats subjected to experimental HPA [84], as well as decreased serum ubiquinone-10 (Coenzyme Q) concentrations in phenylketonuric patients [85]. On the other hand, Kyprianou and colleagues [86] showed no significant difference in mitochondrial respiratory chain complex I (EC \# 1.6.5.3) activity in astrocytoma cells between PKU patients with or without tremor, suggesting that Phe neurotoxicity towards PKU patients does not involve the parameter of mitochondrial respiratory function. Respiratory chain complex II-III activity was also not altered in blood mononuclear cells from phenylketonuric patients [87].

Creatine kinase (CK; EC \#2.7.3.2) activity, a key enzyme for maintenance of ATP homeostasis [88], is significantly inhibited in vitro by Phe and in cerebral cortex of rats subjected to experimental HPA. These results suggest another putative pathological mechanism through which Phe induces neurometabolic alterations in PKU patients [89].

Berti and colleagues [90] showed that bilateral administration of creatine or pyruvate into hippocampus significantly prevented the cognitive impairment triggered by Phe administration in rats in the open field apparatus, indicating that cognitive impairment found in phenylketonuric patients might be secondary to energy failure. Significant beneficial effect of creatine and pyruvate administration was confirmed by the prevention of adenylate kinase (EC \# 2.7.4.3), mitochondrial and cytosolic CK activities impairment in cerebral cortex and 
hippocampus from pregnant and lactating rats receiving high Phe administration, corroborating the hypothesis of impaired energy metabolism on Phe neurotoxicity [91].

Phe and its metabolites also interfere on ketone bodies metabolism through inhibition of 3-hydroxybutyrate dehydrogenase (EC \# 1.1.1.30) and 3-oxo-acid CoAtransferase (EC \# 2.8.3.5) activities in brain of suckling rats [92]. In addition, PPA inhibited pyruvate plus malate oxidation in human and rat skeletal muscle possible due to inhibition of pyruvate dehydrogenase complex (EC \# 1.2. 4.1, EC \# 2.3.1.12, EC \# 1.8.1.4) activity, which could collaborate to the increased lactate levels found in PKU patients [93]. Furthermore, Phe and PPA inhibited pyruvate kinase (EC \# 2.7.1.40) and hexokinase (EC \# 2.7.1.1) activities in adult human and fetal brain samples [94], as well as in brain of rats submitted to HPA experimental model $[95,96]$.

Considering that metal ions (e.g. zinc, iron, and magnesium) are key components of metabolic enzymes [97], acting as regulatory entities on such proteins [15,98], and that they are deficient in PKU patients (as already mentioned), it cannot be ruled that the energy dysfunction observed in PKU may be ascribed to metal ion imbalances that disturb the activity of crucial enzymes of intermediary metabolism. Taken together, these data indicate that disturbances in cell bioenergetics homeostasis may contribute to Phe neurotoxicity observed in PKU.

\section{Calcium Homeostasis}

Calcium homeostasis is crucial for brain function and its disregulation in PKU was suggested by several works. In this context, parathyroid hormone (hormone that regulates calcium metabolism), osteocalcin, and dehydrocholecalciferol were found increased in serum samples from phenylketonuric infants, but calcitonin was found reduced. These alterations were not reverted by Phe-restricted diet [99]. In another study, $\mathrm{Yu}$ and colleagues [100] demonstrated that Phe alters intracellular free calcium concentrations by modulating plasma membrane $\mathrm{Ca}^{2+}$-ATPase in cortical neurons.

\section{Final considerations}

Although the pathophysiological mechanisms of the brain damage found in phenylketonuric patients are not clearly understood yet, there are many evidences of metabolic alterations both in patients and in animal models. Such alterations include bioenergetics deficit, oxidative stress, impairment of lipid and protein metabolism, and disruption of calcium homeostasis and neurotransmitter synthesis in the brain (Figure 2). Taken together, these metabolic disturbances might collaborate to the cognitive dysfunction and brain pathology of PKU.

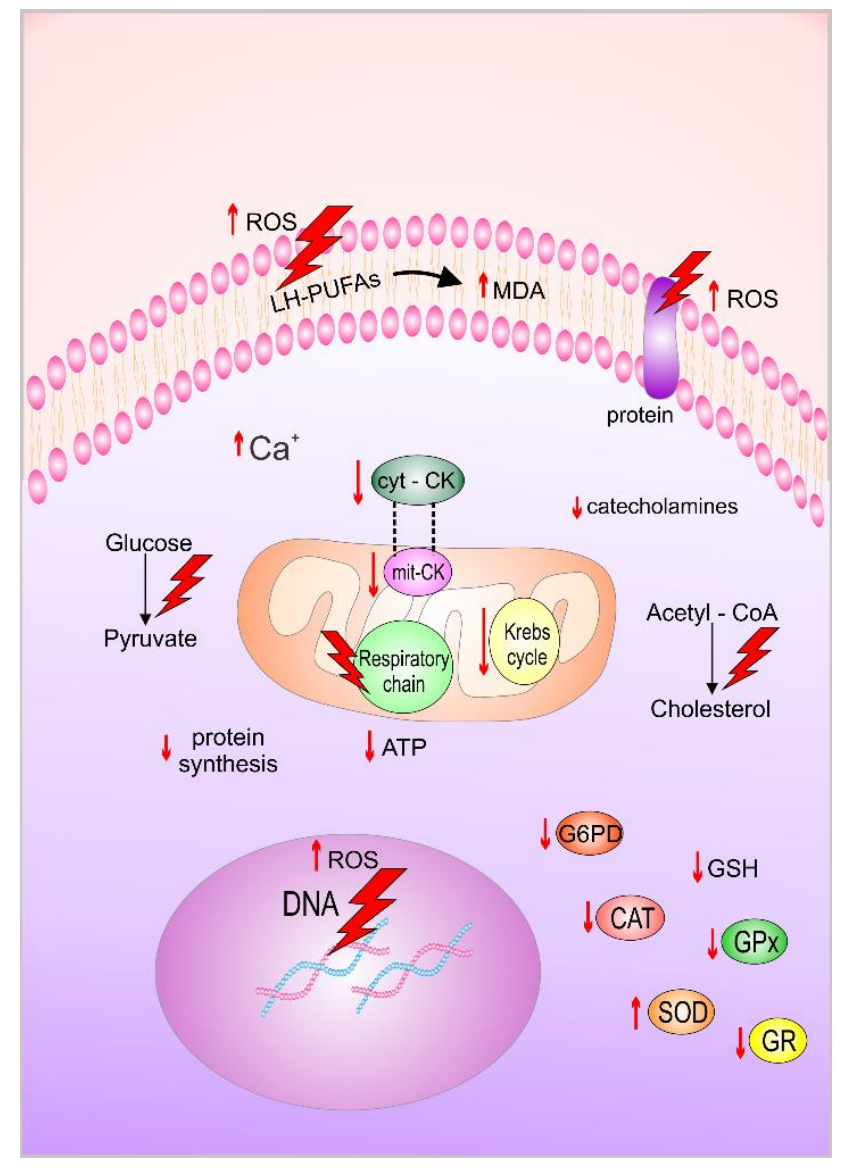

Figure 2. Metabolic alterations involved in the pathophysiology of the brain damage found in phenylketonuric patients. Phenylalanine and its metabolites elicit oxidation of lipids, proteins, and DNA by increasing ROS production and decreasing antioxidant defenses. Bioenergetics is also impaired due to decreased glucose oxidation and alterations of activities of enzymes such as respiratory chain complexes, Krebs cycle enzymes, and creatine kinase. Toxic metabolites also decrease protein, neurotransmitter, and cholesterol synthesis and alter $\mathrm{Ca}^{2+}$ metabolism. ATP, adenosine triphosphate; CAT, catalase; cyt-CK, cytosolic creatine kinase; DNA, desoxiribonucleic acid; G6PD, glucose-6-phosphate dehydrogenase; GPx, glutathione peroxidase; GR, glutathione reductase; GSH, reduced glutathione; MDA, malondialdehyde, mit-CK, mitochondrial creatine kinase; PUFAS, polyunsaturated fatty acid; ROS, reactive oxygen species; SOD, superoxide dismutase.

It is important to stress out that Phe-restricted diet is effective in preventing the brain damage but the recovery of settled damage is not reached with current therapy. In this scenario, due to the improvement of newborn screening in the past years, the life expectancy of 
phenylketonuric patients has increased. It was reported that deterioration of intelligence does not appear to aggravate after adolescence, but psychiatric problems frequently does [101]. Adult PKU patients present decreased brain glucose metabolism in the prefrontal and visual cortices [102], but the metabolic profile and clinical findings characteristic of adult patients are still to be revealed in PKU. That said we believe that the knowledge of the exact mechanisms underlying PKU pathophysiology is pivotal to allow the establishment of more effective therapeutic strategies for phenylketonuric patients at the different stages of life.

\section{Acknowledgements}

The authors would like to thank Jéssica de Assis Goularte for the beautiful picture produced specially for this article. PFS, GCF, ELS and FC receive personal grants from Conselho Nacional de Desenvolvimento Científico e Tecnológico (CNPq). FM and JHC receive fellowships from Fundação de Apoio à Pesquisa Científica e Tecnológica do Estado de Santa Catarina (FAPESC) and Coordenação de Aperfeiçoamento de Pessoal de Nível Superior (CAPES), respectively.

\section{References}

[1] Williams RA, Mamotte CD, Burnett JR (2008). Phenylketonuria: an inborn error of phenylalanine metabolism. Clin Biochem Rev, 29:31-41.

[2] Velema M, Boot E, Engelen M, Hollak C (2015). Parkinsonism in phenylketonuria: a consequence of dopamine depletion? JIMD Rep, 20:35-8.

[3] Kaufman S (1976). The phenylalanine hydroxylating system in phenylketonuria and its variants. Biochem Med, 15:42-54.

[4] Scriver CR, Kaufman S (2001). Hyperphenylalaninemia: phenylalanine hydroxylase deficiency. In: Scriver CR, Beaudet AL, Sly SW, Valle $\mathrm{D}$, editors. The Metabolic and Molecular Bases of Inherited Disease. New York: McGraw-Hill, 1667-724.

[5] Scriver CR, Rosenberg LE (1973). Amino acid metabolism and its disorders. Major Probl Clin Pediatr, 10:1-478.

[6] Rampini S, Völlmin JA, Bosshard HR, Müller M, Curtius HC (1974). Aromatic acids in urine of healthy infants, persistent hyperphenylalaninemia, and phenylketonuria, before and after phenylalanine load. Pediatr Res, 8:704-9.

[7] Scriver CR, Donlon J, Levy H (2008). Hyperphenylalaninemia: phenylalanine hydroxylase deficiency. In: Valle D, Beaudet AL, Vogelstein B, Kinzler KW, Antonarakis SE, Ballabio A, editors. The Online Metabolic and Molecular Bases of Inherited Disease. New York: McGraw-Hill.

[8] Lidsky AS, Law ML, Morse HG, Kao FT, Rabin M, Ruddle FH et al (1985). Regional mapping of the phenylalanine hydroxylase gene and the phenylketonuria locus in the human genome. Proc Natl Acad Sci U S A, 82:6221-5.

[9] Réblová K, Kulhánek P, Fajkusová L (2015). Computational study of missense mutations in phenylalanine hydroxylase. J Mol Model, 21:70.

[10] Camp KM, Parisi MA, Acosta PB, Berry GT, Bilder DA, Blau N et al (2014). Phenylketonuria Scientific Review Conference: state of the science and future research needs. Mol Genet Metab, 112:87-122.

[11] Pimentel FB, Alves RC, Oliva-Teles MT, Costa AS, Fernandes TJ, Almeida MF et al (2014). Targeting specific nutrient deficiencies in protein-restricted diets: some practical facts in PKU dietary management. Food Funct, 5:3151-9.

[12] Trefz F, Maillot F, Motzfeldt K, Schwarz M (2011). Adult phenylketonuria outcome and management. Mol Genet Metab, 104 Suppl:S26-30.

[13] Berry SA, Brown C, Grant M, Greene CL, Jurecki E, Koch J et al (2013). Newborn screening 50 years later: access issues faced by adults with PKU. Genet Med, 15:591-9.

[14] Robert M, Rocha JC, van Rijn M, Ahring K, BélangerQuintana A, MacDonald A et al (2013). Micronutrient status in phenylketonuria. Mol Genet Metab, 110 Suppl:S6-17.

[15] Ragsdale S (2010). Metal-carbon bonds in enzymes and cofactors. Coord Chem Rev, 254:1948-9.

[16] McMurry MP, Chan GM, Leonard CO, Ernst SL (1992). Bone mineral status in children with phenylketonuria--relationship to nutritional intake and phenylalanine control. Am J Clin Nutr, 55:997-1004.

[17] Wilke BC, Vidailhet M, Richard MJ, Ducros V, Arnaud J, Favier A (1993). Trace elements balance in treated phenylketonuria children. Consequences of selenium deficiency on lipid peroxidation. Arch Latinoam Nutr, 43:119-22.

[18] Dyer CA (2000). Comments on the neuropathology of phenylketonuria. Eur J Pediatr, 159 Suppl 2:S107-8.

[19] Huttenlocher PR (2000). The neuropathology of phenylketonuria: human and animal studies. Eur J Pediatr, 159 Suppl 2:S102-6.

[20] Rocha JC, Martel F (2009). Large neutral amino acids supplementation in phenylketonuric patients. J Inherit Metab Dis, 32:472-80.

[21] Duarte JM, Schuck PF, Wenk GL, Ferreira GC (2013). Metabolic disturbances in diseases with neurological involvement. Aging Dis, 5:238-55.

[22] Halliwell B, Gutteridge JMC, editors. Free radicals in biology and medicine. New York: Oxford University Press Inc; 2007.

[23] Pérez-Severiano F, Ríos C, Segovia J (2000). Striatal oxidative damage parallels the expression of a neurological phenotype in mice transgenic for the mutation of Huntington's disease. Brain Res, 862:2347.

[24] Bogdanov MB, Andreassen OA, Dedeoglu A, Ferrante RJ, Beal MF (2001). Increased oxidative damage to DNA in a transgenic mouse model of Huntington's disease. J Neurochem, 79:1246-9. 
[25] Karelson E, Bogdanovic N, Garlind A, Winblad B, Zilmer K, Kullisaar T et al (2001). The cerebrocortical areas in normal brain aging and Alzheimer's disease: noticeable differences in the lipid peroxidation level and antioxidant defense. Neurochem Res, 26:353-61.

[26] Méndez-Alvarez E, Soto-Otero R, Hermida-Ameijeiras A, López-Martín ME, Labandeira-García JL (2001). Effect of iron and manganese on hydroxyl radical production by 6-hydroxydopamine: mediation of antioxidants. Free Radic Biol Med, 31:986-98.

[27] Behl C, Moosmann B (2002). Antioxidant neuroprotection in Alzheimer's disease as preventive and therapeutic approach. Free Radic Biol Med, 33:182-91.

[28] Behl C, Moosmann B (2002). Oxidative nerve cell death in Alzheimer's disease and stroke: antioxidants as neuroprotective compunds. Biol Chem, 383:521-36.

[29] Stoy N, Mackay GM, Forrest CM, Christofides J, Egerton M, Stone TW et al (2005). Tryptophan metabolism and oxidative stress in patients with Huntington's disease. J Neurochem, 93:611-23.

[30] Berg D, Youdim MB (2006). Role of iron in neurodegenerative disorders. Top Magn Reson Imaging, 17:5-17.

[31] Schulpis KH, Tsakiris S, Traeger-Synodinos J, Papassotiriou I (2005). Low total antioxidant status is implicated with high 8-hydroxy-2-deoxyguanosine serum concentrations in phenylketonuria. Clin Biochem, 38:239-42.

[32] Sitta A, Manfredini V, Biasi L, Treméa R, Schwartz IV, Wajner $\mathrm{M}$ et al (2005). Evidence that DNA damage is associated to phenylalanine blood levels in leukocytes from phenylketonuric patients. Mutat Res, 679:13-6.

[33] Sirtori LR, Dutra-Filho CS, Fitarelli D, Sitta A, Haeser A, Barschak AG et al (2005). Oxidative stress in patients with phenylketonuria. Biochim Biophys Acta, 1740:68-73.

[34] Sitta A, Barschak AG, Deon M, Barden AT, Biancini GB, Vargas PR et al (2009). Effect of short- and longterm exposition to high phenylalanine blood levels on oxidative damage in phenylketonuric patients. Int J Dev Neurosci, 27:243-7.

[35] Sitta A, Barschak AG, Deon M, de Mari JF, Barden AT, Vanzin CS et al (2009). L-carnitine blood levels and oxidative stress in treated phenylketonuric patients. Cell Mol Neurobiol, 29:211-8.

[36] Sanayama Y, Nagasaka H, Takayanagi M, Ohura T, Sakamoto O, Ito T et al (2011). Experimental evidence that phenylalanine is strongly associated to oxidative stress in adolescents and adults with phenylketonuria. Mol Genet Metab, 103:220-5.

[37] Sitta A, Vanzin CS, Biancini GB, Manfredini V, de Oliveira AB, Wayhs CA et al (2011). Evidence that Lcarnitine and selenium supplementation reduces oxidative stress in phenylketonuric patients. Cell Mol Neurobiol, 31:429-36.

[38] Ercal N, Aykin-Burns N, Gurer-Orhan H, McDonald JD (2002). Oxidative stress in a phenylketonuria animal model. Free Radic Biol Med, 32:906-11.
[39] Kienzle Hagen ME, Pederzolli CD, Sgaravatti AM, Bridi R, Wajner M, Wannmacher CM et al (2002). Experimental hyperphenylalaninemia provokes oxidative stress in rat brain. Biochim Biophys Acta, 1586:344-52.

[40] Martinez-Cruz F, Pozo D, Osuna C, Espinar A, Marchante C, Guerrero JM (2002). Oxidative stress induced by phenylketonuria in the rat: prevention by melatonin, vitamin $\mathrm{E}$, and vitamin $\mathrm{C}$. J Neurosci Res, 69:550-8.

[41] Fernandes CG, Leipnitz G, Seminotti B, AmaralAU, Zanatta A, Vargas CR et al (2010). Experimental evidence that phenylalanine provokes oxidative stress in hippocampus and cerebral cortex of developing rats. Cell Mol Neurobiol, 30:317-26.

[42] Moraes TB, Zanin F, da Rosa A, de Oliveira A, Coelho J, Petrillo F et al (2010). Lipoic acid prevents oxidative stress in vitro and in vivo by an acute hyperphenylalaninemia chemically-induced in rat brain. J Neurol Sci, 292:89-95.

[43] Moraes TB, Jacques CE, Rosa AP, Dalazen GR, Terra M, Coelho JG et al (2013). Role of catalase and superoxide dismutase activities on oxidative stress in the brain of a phenylketonuria animal model and the effect of lipoic acid. Cell Mol Neurobiol, 33:253-60.

[44] Deon M, Landgraf SS, Lamberty JF, Moura DJ, Saffi J, Wajner M et al (2015). Protective effect of L-carnitine on Phenylalanine-induced DNA damage. Metab Brain Dis, 30:925-33.

[45] Simon KR, Dos Santos RM, Scaini G, Leffa DD, Damiani AP, Furlanetto CB et al (2013). DNA damage induced by phenylalanine and its analogue $\mathrm{p}$ chlorophenylalanine in blood and brain of rats subjected to a model of hyperphenylalaninemia. Biochem Cell Biol, 91:319-24.

[46] Rosa AP, Jacques CE, Moraes TB, Wannmacher CM, Dutra Ade M, Dutra-Filho CS (2012). Phenylpyruvic acid decreases glucose-6-phosphate dehydrogenase activity in rat brain. Cell Mol Neurobiol, 32:1113-8.

[47] Yuwiler A, Geller E, Slater GG (1965). On the mechanism of the brain serotonin depletion in experimental phenylketonuria. J Biol Chem, 240:11704.

[48] Güttler F, Lou H (1986). Dietary problems of phenylketonuria: effect on CNS transmitters and their possible role in behaviour and neuropsychological function. J Inherit Metab Dis, 9 Suppl 2:169-77.

[49] Yano S, Moseley K, Azen C (2013). Large neutral amino acid supplementation increases melatonin synthesis in phenylketonuria: a new biomarker. J Pediatr, 162:999-1003.

[50] Pascucci T, Ventura R, Puglisi-Allegra S, Cabib S (2002). Deficits in brain serotonin synthesis in a genetic mouse model of phenylketonuria. Neuroreport, 13:2561-4.

[51] Landvogt C, Mengel E, Bartenstein P, Buchholz HG, Schreckenberger M, Siessmeier T et al (2008). Reduced cerebral fluoro-L-dopamine uptake in adult patients 
suffering from phenylketonuria. J Cereb Blood Flow Metab, 28:824-31.

[52] Sawin EA, Murali SG, Ney DM (2014). Differential effects of low-phenylalanine protein sources on brain neurotransmitters and behavior in C57BI/6-Pah(enu2) mice. Mol Genet Metab, 111:452-61.

[53] Pietz J, Kreis R, Rupp A, Mayatepek E, Rating D, Boesch C et al (1999). Large neutral amino acids block phenylalanine transport into brain tissue in patients with phenylketonuria. J Clin Invest, 103:1169-78.

[54] McKean CM (1972). The effects of high phenylalanine concentrations on serotinin and catecholamine metabolism in the human brain. Brain Res, 47:469-76.

[55] Sandler M (1982). Inborn errors and disturbances of central neurotransmission (with special reference to phenylketonuria). J Inherit Metab Dis, 5:65-70.

[56] Christensen HN, Streicher JA, Elbinger RL (1948). Effects of feeding individual amino acids upon the distribution of other amino acids between cells and extracellular fluid. J Biol Chem, 172:515-24.

[57] Choi TB, Pardridge WM (1986). Phenylalanine transport at the human blood-brain barrier. Studies with isolated human brain capillaries. J Biol Chem, 261:6536-41.

[58] Diamond A, Herzberg C (1996). Impaired sensitivity to visual contrast in children treated early and continuously for phenylketonuria. Brain, 119:523-38.

[59] Gramer G, Förl B, Springer C, Weimer P, Haege G, Mackensen $F$ et al (2013). Visual functions in phenylketonuria-evaluating the dopamine and longchain polyunsaturated fatty acids depletion hypotheses. Mol Genet Metab, 108:1-7.

[60] Harding CO, Winn SR, Gibson MK, Arning E, Bottiglieri T, Grompe M (2014). Pharmacologic inhibition of L-tyrosine degradation ameliorates cerebral dopamine deficiency in murine phenylketonuria (PKU). J Inherit Metab Dis, 37:73543 .

[61] Justice P, Hsia DY (1965). Studies on inhibition of brain 5-hydroxytryptophan decarboxylase by phenylalanine metabolites. Proc Soc Exp Biol Med, 118:326-8

[62] Agrawal HC, Bone AH, Davison AN (1970). Effect of phenylalanine on protein synthesis in the developing rat brain. Biochem J, 117:325-31.

[63] Elsliger MA, Thériault GR, Gauthier D (1989). In vitro localization of the protein synthesis defect associated with experimental phenylketonuria. Neurochem Res, 14:81-4.

[64] Pardridge WM (1998). Blood-brain barrier carriermediated transport and brain metabolism of amino acids. Neurochem Res, 23:635-44.

[65] de Groot MJ, Hoeksma M, Reijngoud DJ, de Valk HW, Paans AM, Sauer PJ et al (2013). Phenylketonuria: reduced tyrosine brain influx relates to reduced cerebral protein synthesis. Orphanet J Rare Dis, 8:133.

[66] de Groot MJ, Sijens PE, Reijngoud DJ, Paans AM, van Spronsen FJ (2015). Phenylketonuria: brain phenylalanine concentrations relate inversely to cerebral protein synthesis. J Cereb Blood Flow Metab, 35:200-5.

[67] Smith CB, Kang J (2000). Cerebral protein synthesis in a genetic mouse model of phenylketonuria. Proc Natl Acad Sci U S A, 97:11014-9.

[68] Hoeksma M, Reijngoud DJ, Pruim J, de Valk HW, Paans AM, van Spronsen FJ (2009). Phenylketonuria: high plasma phenylalanine decreases cerebral protein synthesis. Mol Genet Metab, 96:17782.

[69] Gropper SS, Chaung HC, Bernstein LE, Trahms C, Rarback S, Weese SJ (1995). Immune status of children with phenylketonuria. J Am Coll Nutr, 14:26470 .

[70] Imperlini E, Orrù S, Corbo C, Daniele A, Salvatore F (2014). Altered brain protein expression profiles are associated with molecular neurological dysfunction in the PKU mouse model. J Neurochem, 129:1002-12.

[71] Rocha JC, Martins MJ (2012). Oxidative stress in phenylketonuria: future directions. J Inherit Metab Dis, 35:381-98.

[72] Nagasaka H, Tsukahara H, Okano Y, Hirano K, Sakurai T, Hui SP et al (2014). Changes of lipoproteins in phenylalanine hydroxylase-deficient children during the first year of life. Clin Chim Acta, 433:1-4.

[73] Shefer S, Tint GS, Jean-Guillaume D, Daikhin E, Kendler A, Nguyen LB et al (2000). Is there a relationship between 3-hydroxy-3-methylglutaryl coenzyme a reductase activity and forebrain pathology in the PKU mouse? J Neurosci Res, 61:549-63.

[74] Castillo M, Martinez-Cayuela M, Zafra MF, GarciaPeregrin E (1991). Effect of phenylalanine derivatives on the main regulatory enzymes of hepatic cholesterogenesis. Mol Cell Biochem, 105:21-5.

[75] Nagasaka H, Okano Y, Kimura A, Mizuochi T, Sanayama Y, Takatani T et al (2013). Oxysterol changes along with cholesterol and vitamin $\mathrm{D}$ changes in adult phenylketonuric patients diagnosed by newborn mass-screening. Clin Chim Acta, 416:54-9.

[76] Giovannini M, Verduci E, Radaelli G, Lammardo A, Minghetti D, Cagnoli $G$ et al (2011). Long-chain polyunsaturated fatty acids profile in plasma phospholipids of hyperphenylalaninemic children on unrestricted diet. Prostaglandins Leukot Essent Fatty Acids, 84:39-42.

[77] Cockburn F, Clark BJ, Caine EA, Harvie A, Farquharson J, Jamieson EC (1996). Fatty acids in the stability of the neuronal membrane: relevance to PKU. Int Pediatr, 11:56-60.

[78] Lohner S, Fekete K, Decsi T (2013). Lower n-3 longchain polyunsaturated fatty acid values in patients with phenylketonuria: a systematic review and metaanalysis. Nutr Res, 33:513-20.

[79] Infante JP, Huszagh VA (2001). Impaired arachidonic (20:4n-6) and docosahexaenoic (22:6n-3) acid synthesis by phenylalanine metabolites as etiological factors in the neuropathology of phenylketonuria. Mol Genet Metab, 72:185-98

[80] Schuck PF, Ferreira GC, Moura AP, Busanello EN, Tonin AM, Dutra-Filho CS et al (2009). Medium-chain 
fatty acids accumulating in MCAD deficiency elicit lipid and protein oxidative damage and decrease nonenzymatic antioxidant defenses in rat rain. Neurochem Int, 548:519-25.

[81] Amaral AU, Leipnitz G, Fernandes CG, Seminotti B, Schuck PF, Wajner M. Alpha-ketoisocaproic acid and leucine provoke mitochondrial bioenergetic dysfunction in rat brain. Brain Res, 1324:75-84.

[82] Melo DR, Kowaltowski AJ, Wajner M, Castilho RF (2011). Mitochondrial energy metabolism in neurodegeneration associated with methylmalonic acidemia. J Bioenerg Biomembr, 43:39-46.

[83] Wajner M, Goodman SI (2011). Disruption of mitochondrial homeostasis in organic acidurias: insights from human and animal studies. J Bioenerg Biomembr, 43:31-8.

[84] Rech VC, Feksa LR, Dutra-Filho CS, Wyse AT, Wajner M, Wannmacher CM (2002). Inhibition of the mitochondrial respiratory chain by phenylalanine in rat cerebral cortex. Neurochem Res, 27:353-7.

[85] Artuch R, Vilaseca MA, Moreno J, Lambruschini N, Cambra FJ, Campistol J (1999). Decreased serum ubiquinone-10 concentrations in phenylketonuria. Am J Clin Nutr, 70:892-5.

[86] Kyprianou N, Murphy E, Lee P, Hargreaves I (2009). Assessment of mitochondrial respiratory chain function in hyperphenylalaninaemia. $\mathrm{J}$ Inherit Metab Dis, 32:289-96.

[87] Hargreaves IP, Heales SJ, Briddon A, Land JM, Lee PJ (2002). Blood mononuclear cell coenzyme Q10 concentration and mitochondrial respiratory chain succinate cytochrome-c reductase activity in phenylketonuric patients. J Inherit Metab Dis, 25:6739.

[88] Wallimann T, Tokarska-Schlattner M, Schlattner U (2011). The creatine kinase system and pleiotropic effects of creatine. Amino Acids, 40:1271-96.

[89] Costabeber E, Kessler A, Severo Dutra-Filho C, de Souza Wyse AT, Wajner M, Wannmacher CM (2003). Hyperphenylalaninemia reduces creatine kinase activity in the cerebral cortex of rats. Int $\mathrm{J}$ Dev Neurosci, 21:111-6.

[90] Berti SL, Nasi GM, Garcia C, Castro FL, Nunes ML, Rojas DB et al (2012). Pyruvate and creatine prevent oxidative stress and behavioral alterations caused by phenylalanine administration into hippocampus of rats. Metab Brain Dis, 27:79-89.

[91] Bortoluzzi VT, de Franceschi ID, Rieger E, Wannmacher CM (2014). Co-administration of creatine plus pyruvate prevents the effects of phenylalanine administration to female rats during pregnancy and lactation on enzymes activity of energy metabolism in cerebral cortex and hippocampus of the offspring. Neurochem Res, 39:1594-602.

[92] Benavides J, Gimenez C, Valdivieso F, Mayor F (1976). Effect of phenylalanine metabolites on the activities of enzymes of ketone-body utilization in brain of suckling rats. Biochem J, 160:217-22.

[93] Swierczyński J, Aleksandrowicz Z, Zydowo M (1976). Inhibition of pyruvate oxidation by skeletal muscle mitochondria by phenylpyruvate. Acta Biochim Pol, 23:85-92.

[94] Weber G (1969). Inhibition of human brain pyruvate kinase and hexokinase by phenylalanine and phenylpyruvate: possible relevance to phenylketonuric brain damage. Proc Natl Acad Sci U S A, 63:1365-9.

[95] Lütz Mda G, Feksa LR, Wyse AT, Dutra-Filho CS, Wajner M, Wannmacher CM (2003). Alanine prevents the in vitro inhibition of glycolysis caused by phenylalanine in brain cortex of rats. Metab Brain Dis, 18:87-94.

[96] Bortoluzzi VT, de Franceschi ID, Rieger E, Wannmacher CM (2014). Co-administration of creatine plus pyruvate prevents the effects of phenylalanine administration to female rats during pregnancy and lactation on enzymes activity of energy metabolism in cerebral cortex and hippocampus of the offspring. Neurochem Res, 39:1594-602.

[97] Broderick JB, editor. Coenzymes and cofactors. Chichester: John Wiley \& Sons; 2001.

[98] Brown DA, Cook RA (1981). Role of metal cofactors in enzyme regulation. Differences in the regulatory properties of the Escherichia coli nicotinamide adenine dinucleotide phosphate specific malic enzyme, depending on whether magnesium ion or manganese ion serves as divalent cation. Biochemistry, 20:250312.

[99] Bushueva TV, Ladodo KS, Spirichev VB, Denisova SN, Rybakova EP (1993). Calcium homeostasis and calcium-regulating hormones in young children with phenylketonuria. Vopr Pitan, 16-21.

[100] Yu YG, Tang FG, Pan J, Gu XF (2007). Effects of phenylalanine and its metabolites on cytoplasmic free calcium in cortical neurons. Neurochem Res, 32:1292301.

[101] Hanley WB (2004). Adult phenylketonuria. Am J Med, 117:590-5.

[102] Wasserstein MP, Snyderman SE, Sansaricq C, Buchsbaum MS. Cerebral glucose metabolism in adults with early treated classic phenylketonuria (2006). Mol Genet Metab, 87:272-7. 